\title{
NON PHARMACOLOGICAL APPROACHES IN THE MANAGEMENT OF DIABETES MELLITUS
}

\section{RAMAM SRIPADA*, HEMANTH KUMAR VANGALA, SUDEEPTHI PADALA, DASARATHA DHANARAJU MAGHARLA}

Department of Pharmacy Practice, GIET School of Pharmacy, Rajahmundry, Andhra Pradesh, India. Email: ramampharmd7@gmail.com

\author{
Received: 23 July 2019, Revised and Accepted: 12 August 2019
}

\begin{abstract}
Diabetes can be defined as a metabolic disorder characterized by resistance to the action of insulin, insufficient insulin secretion, or both. In this article, we reviewed about the non-pharmacological approaches in the management of diabetes mellitus that includes diet and stress management programs such as Pranayama, meditation, and exercises along with the lifestyle modification which has to be followed by the diabetics for the better management of diabetes in natural ways. By following, these approaches besides regular usage of medications one can lead a healthy life with very less complications. The quality of life can be increased in the patients who follow these methods when compared to those patients who do not consider any of these methods in their daily life. Not only the patient, a healthy individual but can also prefer these methods to prevent chronic diseases and make their day to day life happy and healthy.
\end{abstract}

Keywords: Diabetes, Diabetic diet, Diabetic Yoga, Meditation, Pranayama

(C) 2019 The Authors. Published by Innovare Academic Sciences Pvt Ltd. This is an open access article under the CC BY license (http://creativecommons. org/licenses/by/4. 0/) DOI: http://dx.doi.org/10.22159/ajpcr.2019.v12i10. 35048

\section{INTRODUCTION}

\section{Diabetes}

Diabetes can be defined as a metabolic disorder characterized by resistance to the action of insulin, insufficient insulin secretion, or both. Insulin is a hormone secreted from the pancreatic cells called beta cells. This hormone regulates the blood glucose levels in the body by pumping glucose from food into cells to produce energy. Sometimes body neither produces enough insulin nor utilizes secreted insulin well. Thereby glucose does not reach cells and remains in blood that leads to elevated levels of blood glucose. The most common types of diabetes are type-I, type-II, and gestational diabetes. Type-I diabetes is a condition where body does not produce enough insulin. Immune system attacks and destroys the beta cells in pancreas which produce insulin. Type-I diabetes is usually diagnosed in children and young adults. Type-II is the most common type of diabetes, where the body does not utilize insulin well. Type-II diabetes can be developed at any age, even during childhood. However, this type of diabetes occurs most often in middleaged and older people. Gestational diabetes can be developed by some women during their pregnancy and is cured after the delivery. However, gestational diabetes has a greater chance of developing type-II diabetes later in life. However, diabetes diagnosed during pregnancy is usually of type-II. Factors such as age ( $\geq 45$ years), family history of diabetes, overweight, physical inactivity, race, and certain health-related problems such as high blood pressure had chances of developing typeII diabetes. In medical history, diabetes has shown a great impact on the health-care sector that resembles the burden in diagnosing, treating and managing it in a prominent way [1-6].

\section{HISTORY}

In the year $1552 \mathrm{BC}$, Egyptian physician Hesy-Ra first described this illness associated with the passage of much urine. The name diabetes was given by Greek physician Aretaeus of Cappadocia. In the $3^{\text {rd }}-6^{\text {th }}$ century, AD scholars in China, Japan, and India described that this condition was associated with polyuria, where the urine was sticky and sweet. Willis Dobson stated that the sweetness of urine was due to presence of sugar in it.

The chemical test for identifying sugar in urine was first put forward in $1000 \mathrm{AD}$ by an Arab physician Avicenna. During rationing of food in Paris, while under siege by Germany during Franco-Prussian war, the disappearance of glycosuria was observed by Apollinaire Bouchardat, a French physician in diabetic patients. Hence, he formulated an idea of individualization of diet in diabetic patients. In 1919, Frederick Allen observed that reduced calorie intake in diabetic patients decreases the amount of sugar levels in urine by giving low-calorie diet as low as 450 calories/day.

The working of pancreas and glucose metabolism in liver was first studied by French researcher Claude Bernard in the $19^{\text {th }}$ century. Nanyn, Minkowski, Opie Schafer, and Oyhers conducted a study and observed that diabetes is caused due to lack of hormone secreted by pancreatic cells known as islets of Langerhans and later Schafer named this hormone as insulin. Based on insulin sensitivity, Hinsword classified diabetes as two types, Type-I (insulin sensitivity) and Type-II (insulin resistant). Eli Lilly and company is first to produce large quantity of purified insulin which is obtained from animal sources. In 1960 Dorothy frank developed urine strips to check the sugar levels in urine, and Dr. Richard Bernstein developed the first portable glucometer in 1969 [7].

For Type-I diabetes mellitus (DM), insulin is the only medication as it is insulin-dependent, but type-II is non-insulin dependent so, many drugs such as oral hypoglycemic agents, glucagon-like peptide-I receptor agonists, and insulin are available. Some drugs such as metformin, glimepiride, repaglinide, and pioglitazone are commonly used oral hypoglycemic agents in treatment of DM. Sometimes combinations of two or more drugs are used in uncontrolled DM [8].

Along with medication therapy in diabetes, lifestyle modifications should also be implemented to avoid complications and to lead a better life. Apart from medications there are some natural methods which help in controlling the blood glucose levels and stimulate the pancreas to release insulin. This natural method helps in promoting a better life for the people who are living with diabetes. In this article, we mainly reviewed some of the natural methods to be followed in diabetes along with usage of usual diabetic treatments.

\section{NATURAL METHODS FOR CONTROLLING DM}

Diet

The patients who are diabetic no longer be able to eat normally are a myth [9]. Paleolithic diet should be followed which includes fish, nuts, vegetables, and seeds show some glucose tolerance [10]. Indians were 
recommended with new dietary guidelines by the diabetes foundation by considering some important factors such as calorie intake as per body weight, calculation of ideal body weight, and number of servings for different food groups [11].

Australian chef Michael Moore classified foods into three categories that include fire, water, and coal. Fire foods: These foods include white rice, white bread, white pasta, potatoes, chips, and sweets. These foods should be limited in diabetic diet. These foods are low in fiber and protein and have fats. Water foods: These foods include vegetables and fruits. Coal foods: These foods include nuts, seeds, whole grains. These foods are rich in protein and fibers and have low fats [12].

American diabetic association advised a formula known as "Dinner type of Diet." This involves, on every 14 or 15 days, the patient can eat whatever he/she wish in a limited quantity but during the other days patient should strictly adhere to the prescribed diet. This formula helps the patient to reduce the craving for sweets and also helps to decrease the depressive feeling because of the disease. In case of noninsulin dependent DM (NIDDM), patient's diet plays a crucial role in the control of blood glucose levels. Diabetics UK has warned about the products that are made especially for diabetic patients as the products were very expensive and do not provide any special benefits. The patients need to be aware of these products before purchasing.

A diabetic patient should never skip breakfast and should definitely have three meals and one or two snacks each day [13]. In case of gestational diabetes in women, therapeutic lifestyle changes (TLC) diet which should be followed by the diabetic patients with abnormal cholesterol levels. TLC diet includes $25 \%$ of total fat consumption $[14,15]$. Foods with artificial sweeteners such as aspartame, acesulfamepotassium, saccharine, and sucralose should be avoided as they tend to accumulation of fats in the body [16].

\section{Carbohydrates and sweeteners}

Carbohydrate intake affects blood glucose levels. Thus, carbohydrate foods with lower glycemic index such as starchy food such as wholemeal parts and whole grains, pulses, brown rice or wild rice, and brown bread are to be selected. White bread, oatmeal, and pastries are to be avoided. Prefer green leafy vegetables rich in fiber; avoid carbohydrate-rich fruits such as apple and fleshy fruits because they contain fructose. When sudden hypoglycemic condition was observed in patient with diabetes, low ceiling carbohydrates such as rye bread and cereals bananas are advisable. Avoid sugar drinks because they increase blood glucose levels. Instead prefer sugar-free or low sugar quenchers and fizzy drinks in minute quantity. In the dietary management of type-II diabetes, low carbohydrate intake, i.e., $30 \mathrm{~g} /$ day is advisable. In vegetarians, the incidence of diabetes is low. Thereby vegetarian diet is more effective in case of type-II diabetes and obesity. Timing of food intake plays a crucial role in the management of diabetics. Instead of salt, prefer herbs and spices to flavor the food if necessary. To control diabetes in a better way, take limited intake of calories in five diets serving method such as breakfast, mid-meal, mid-day, evening, and dinner which comprises 3-h gaps between each serving. To balance the overall diet, prefer fruits and vegetables which are rich in vitamins and fibers every day. Fibrous strands admixed with flesh containing fruits such as citrus fruits do not increase the blood sugar level in case of moderate intake [17-23].

Methi coffee, which can be prepared with dried fenugreek seeds and wheat when added with milk, gives a coffee-like taste. Fenugreek seeds are one of the ingredients that help in decreasing the blood sugar level [24].

One can take any food item of their interest in a limited quantity, providing the immediate principle meal was satisfied so that not much of oscillation in blood sugar level will be observed at any point of time. To control and prevent the chronic complications of DM such as coronary artery disease and stroke, non-vegetarian foods should be taken in restricted amounts. Avoid chicken and other protein-rich foods in case of diabetic nephropathy. Salt restriction is advised in case of diabetic patients with hypertension (HTN), and restriction of fatty substances is advised in case of diabetic patients with dyslipidemia. Lemon juice and buttermilk with salt are preferable in the non-hypertensive diabetic patients in order to prevent the chronic complications [25].

\section{Proteins}

It prefers plant-based proteins such as beans, whole grains, and millets. Proteins $<1 \mathrm{~g} / \mathrm{kg}$ of body weight are recommended in case of patients without nephropathy. In case of patients with nephropathy, protein intake is restricted as they cause increased progression of renal failure [26].

\section{Fats}

Fat consumption should be limited in the case of type-II diabetic patients because; obesity is a major complication in them. Out of the total energy consumption, the fat intake should be less than $<35 \%$. Oils such as canola oil and olive oil contain monounsaturated fats. Less than $10 \%$ of fats account for saturated and trans-unsaturated fats, and 10-20\% accounts for monounsaturated fats. Palm oil, cocoa butter, whole milk products, and coconut are rich resources of saturated fats. Hydrogenated vegetable oils are rich source of transunsaturated fats so better avoid them. Sunflower oil, corn seed oil, and soya bean oil are rich sources of N-6 polyunsaturated fats which accounts for $10 \%$ of energy intake and fish oil from fish which is a rich source of N-3 Polyunsaturated fats should be eaten once or twice a week. Avoid butter, cheese, and margarine as they are high-fat content foods, prefer low-fat dairy products such as low-fat yogurt, and skimmed milk [27].

\section{Fibers}

About $50 \mathrm{~g}$ of soluble fiber produces improvement of $10 \%$ in fasting blood glucose, decreases low-density lipoprotein (LDL) and cholesterol in case of an average person with NIDDM. The diet for diabetic patients should be comprised of rich amount of soluble fiber. Yams, winter squash, cauliflower mash, whole wheat pasta, whole grain bread, raisin bran, steel cuts oats, and bran muffin are rich sources of fiber [28].

\section{Remedies through diet modification}

One tablespoon of bitter gourd juice daily is the best remedy for diabetics to reduce the blood sugar level. Bitter gourd can also be cooked with ghee which gives a better result [29]. A tablespoon of Indian gooseberry juice in combination with bitter gourd promotes the secretion of insulin from pancreas [30]. Better results can be obtained on regular usage for 2 months. Drinking a glass of water with neem leaves, tulsi leaves, and bel petras leaves (bael) on empty stomach is suggestible to control diabetes naturally [31]. Fruits such as jambul fruit (black plum) and Indian gooseberry, grains such as Bengal gram and black gram are advisable in case of diet modification [32]. Mushroom helps in showing hypoglycemic effect due to alpha-glycosidase inhibition property which may be more beneficial in the management of diabetes. Reishi, Agrocybe cylindracea, and cordyceps have the property to lower the blood sugar levels [33,34].

\section{DIABETIC STRESS MANAGEMENT}

Stress shows negative effects on patients with type-2 DM. The utility of stress management training shows conflicting evidence in the treatment of diabetics. Some studies reveal that the therapeutic effect of stress management has used time-intensive individual treatment [35-38]. It can be done with the implementation of behavioral stress management programs and also by the use of anxiolytics that reduce stress $[39,40]$. To improve glycemic control in patients with uncontrolled type-2 DM, both the interventions are to be implemented carefully.

\section{Stress management programs include}

- Educating the diabetic patients on the health consequences that may occur due to stress. 
- Developing the cognitive and behavioral skills to minimize the stress levels that include recognizing the significant stresses in the individual and advising to minimize and prevent negative thoughts.

- Progressive muscle relaxation training includes consecutively tensing and relaxing a specific set of muscles in the body, which starts from feet and progresses to the head. Nowadays, audio and video files are available which give instructions about how to practice muscle relaxation at home. Better results can be obtained when done twice a day $[41,42]$.

Any type of stress either physical stress or mental stress may cause changes in the blood sugar levels, especially in diabetic patients. Not only the glycemic control is affected but it can also cause complications such as impaired physical and mental well-being, depression due to social relationships. Flight response of flight freeze is an evolutionary coping mechanism which makes the individual deal with the harmful situation and threats. Many researchers found that high levels of stress may constantly spark to drastic changes in flight freeze or flight response; this leads to difficulty in controlling the blood glucose levels $[43,44]$.

Nowadays, majority of people are suffering from stress-related problems due to job tensions, economic problems, and personal problems. Especially in case of software professionals, meeting deadlines are a major factor that causes stress in many of them. To alleviate stress, yoga, exercises, listening to music, and mindful meditation are the best techniques. A research study from Maastricht University revealed that physical exercise helps in not only burning calories but also helps by increases insulin sensitivity [45].

\section{Pranayama}

Pranayama is defined as the control of motion of inhalation, exhalation, and the retention of vital energy. To attain healthy body and mind, we have to control the rhythm of energy with Pranayama. This technique is not only effective in case of blood pressure, weight complications, and several psychiatric disorders, it also helps in controlling diabetes. Pranayama is the best choice to enhance the oxygen levels and reduce the $\mathrm{CO}_{2}$ levels in the blood. It includes rapid and forceful process of inhalation and exhalation powered by diaphragm. Forced breathing stimulates the olfactory nerve endings in the nostril. When traced toward brain, there are nerve endings which end up as olfactory tract and there are tracts in turn end in olfactory bulbs which are connected to limbic system of the brain. Emotions such as grief and rage will be regulated by the limbic system, when the above neural pathway is stimulated different techniques of Pranayama produces positive emotions and also which decreases the worries and tensions of our daily life. Apart from the insulin injection and medications available in the market Pranayama helps in the management of diabetes. Alternate nostril breathing or Nadi-Shodhan Pranayama is the basic preparation for Pranayama. It produces calming effect on nervous system and stress levels will be reduced. Hence, alternate nostril breathing techniques help in the management of stress in people with diabetes. One round of inhalation and exhalation is equal to one round of bhastrika Pranayama. It produces calming effect on brain and nervous system. To perform Bhastrika Pranayama, we must learn fast breathing, deep breathing, and alternate nostril breathing.

Sit straight in a quiet, well-ventilated corner with eyes closed. Keep a gentle smile and eyes closed for some time. Observe the sensations in the body and the quietness within. There is a cartilage between cheek and ear, place index fingers on the cartilage. Take a deep breath in and breathe out, gently press the cartilage. You can keep the cartilage pressed or press it in and out with fingers while making a loud humming sound like a bee. Low-pitched sound also can be made, but it is good to make a high-pitched sound for better results. Continue the same pattern 3-4 times for few minutes [46-54].

\section{Kapal Bhati Pranayama}

The fitness of humans depends on proper breathing techniques which will enhance the oxygen level in the body, thereby increasing the immunity to all types of diseases. Kapal Bhati Pranayama plays a key role in the effective cure of diabetics.

Early morning is the best time to perform this breathing technique on an empty stomach after completing all the morning rituals. The person should sit in the lotus posture or in Sukharan. Eyes should be completely closed and the palms should be rested on the knees. The thumb of both the hands should touch the index finger to make a circle. All the remaining fingers should be kept straight. This pose is known as Dhyanamudra. Now we have to take slow and deep breathing to relax the body and mind completely. The individual should inhale very slowly and should try to exhale the air out forcibly. The speed of this Pranayama technique should be 1 time/s.

While performing this Pranayama, the very important aspect is, think constantly that all impurities and body ailments are thrown out during forced exhalation. Evidence showed that within a period of 3-5 months hundreds of diabetic patient were cured by performing this unique program technique. Kapal means forehead and Bhati means light. After 3 weeks of this Pranayama, the individuals face starts shining, showing the positive results. The individual has to sit compactable in Vajarana or cross-legged with spine erect. Exhale through both the nostrils. The lower and middle abdomen portions get contracted. These contractions should be released quickly and instantly followed by another forceful exhalation. Breathing effortlessly and passively increases the frequency to 100 times/min. At the end of the round, inhale deeply and exhale gradually. During this exercise, heat will be generated, and this shows a tremendous effect on the respiratory system because it purifies the lungs and nasal pathway. By this technique, carbon dioxide will be eliminated from the body [52,55-57].

\section{Anuloma viloma Pranayama}

It is also called an alternate nostril breathing technique. This technique calms the nerves and strengthens the lungs. This technique not only regulates diabetes but also asthma, chronic headache, insomnia, etc. The head, neck, and spine have to be kept erect. The index and the middle finger of right hand should be folded towards palm and, the thumb should be toward right nostril and ring finger, and little finger should remain toward left nostril. The right nostril should be closed with the thumb and inhales air with the help of left nostril, loose the left nostril with the ring finger and the little finger. Now exhale slowly through right nostril by removing the thumb. After breathing out, breathe in through the same right nostril. After this, close the right nostril with thumb and breathe out through the left nostril. If this technique is performed perfectly for 1 time, one round of Anuloma Viloma technique gets completed [52,47].

\section{Ujjayi technique of Pranayama}

This technique produces heat in the body. It is also called as ocean sounding breath. In this technique inhale the air slowly through the nostrils for about 4-5 heartbeats and exhales the air slowly for about 4-5 heartbeats. An ocean-like sound may be observed when performing this technique. This Pranayama is not only effective in case of respiratory disorders but also in the proper functioning of thyroid gland. Ujjayi Pranayama is contraindicated in case of patients with HTN so better to avoid in such complications [51,58].

\section{Diabetic meditation}

Mindfulness meditation is the art of making awareness about the present situation that includes control of thoughts, emotions, and sensations which should be in a non-judgmental and accepting manner. Studies have shown that mindfulness mediation maintains blood glucose at stable levels in diabetics by accepting or acknowledging destructive emotion in a non-judgmental way.

The health condition of diabetic patients can be declined when they were under stress condition as they may skip the meals or even sometimes medications, which straightly affects their blood sugar levels. Meditation is a practice which can be done in several ways and also in several settings that help our body and mind to relax. 
Meditation helps us to relax in such a way that the stress will be departed.

Nowadays, stress becomes a part of our life. The effect of stress increases blood glucose levels, and most of the people may engage in some habits which badly affect our health, condition such as watching TV while eating. Studies show that by practicing meditation, one can reduce their body weight and can lower the blood pressure which is most important in the management of diabetes. It also helps to relax the brain. It improves the decision making of individual which helps to lead a systematic life. If meditation becomes a regular part of a diabetic individual, it will enhance the attitude and control over the body.

Transcendental meditation is a type of meditation with a silent mantra. It involves the use of mantra and meditates for 20 min twice a day. It mainly influences patients with type- 2 diabetes. Insulin and glucose levels will be increased by the stress hormone such adrenaline, noradrenaline, and cortisol. Transcendental meditation technique balances and reduces these hormones and helps regulation of glucose and insulin in the blood.

Mindfulness meditation helps to learn and live life peacefully. It makes the person with diabetes sit either in a chair or on the floor using a cushion, keep the back straight. It is best adopted when individual pays attention to their own breath. Increasing time of meditation day by day provides peaceful state of mind [59-62].

\section{DIABETIC YOGA}

The main causes of diabetes are obesity, stress, lack of exercise, and genetic factors. The incidence of type-II diabetics will be more in case of obese patients because of the body fat and fat circulating in the bloodstream which interferes with the ability of cells to use insulin.

The level of estrogen and progesterone in our body can also cause changes in blood sugar level, especially during the $3^{\text {rd }}$ week of the menstrual cycle. Most women though do not notice this change. Obesity and diabetes can be considered as twin epidemics.

By figuring the body mass index one can measure, whether the person is overweight or underweight or normal. The factors that cause obesity are genetical, environmental, and psychological. The persons who were adapted to a sedentary lifestyle are more prone to obesity. Drugs such as steroids can cause weight gain in some patients. To facilitate the treatment for this twin epidemic adaptation, yoga lifestyle is more applicable [63].

Yoga poles which are more suitable in case of this twin epidemic are Sun Salualian (Suryanamaskar), Tary pole (Sukharana), half spinal twist (Ardha Matsyendrasana), shoulder stretches, stand spread leg forward fold, double leg raises, tree pose (Tadasana), fish pose (Matsayasana), corpse pose (Savarana), and seated forward bend (Paschimottanasana), hand to toe pose (Pandangusthasana), Tsow pose (Dhanurasana), Shalabhasana (Grasshopper pose), Sithy pose of firmer (Sputa Vajarana), wheel pose (Charasana), spinal twist (Ardha Matsyendrasana), shoulder stand (Sarvangasana), downward-facing dog, triangle pose, western intense pose, hero posture, etc.

To overcome diabetes, adaptation of yoga is the best way in addition to the other lifestyle modifications. Different types of postures and breathing exercises are present in yoga to stimulate the pancreas. In diabetes there are yoga postures that rejuvenate the organ cells and also improve the organ ability to produce insulin by improving the blood flow to the pancreas [64-69]. In case of diabetes all the yoga postures should be practiced or performed before the meals but only after consuming small amount of fluids. It is important to start with simple and primary asana in yoga which helps in diabetes.

\section{Advantages}

Downward facing dog pose calms the mind, improves digestion, and decreases high blood pressure, and this pose also improves blood flow to the liver and kidneys. This, in turn, protects against non-alcoholic fatty liver disease which is one of the complications among diabetic patients and in some conditions diabetes may also lead to renal failure.

Triangle pose helps in stimulating the abdominal organ, and it also improves digestion. Western intense pose and hero pose helps in strengthening the pelvic muscles especially in case of women with diabetes because they may get weak. Half lord of the fish asana improves the circulation of blood to the internal organs particularly to the pancreas which increases glucose sensitivity. Corse pose enables elimination of impurities through sweat and urine.

Sun salutation increases the supply of blood to various parts of the body. The efficient and functioning of the organ increases only when the oxygen and blood supply to the organs increases. Majority of the asana that is recommended for diabetics show positive effect on the pancreas and insulin functioning [51,70-80].

\section{EXERCISE}

The DM patients need exercise which helps in reducing calories and fat deposition in the body. Intake of high-calorie food and lack of exercise causes complications such as stroke and cardiovascular problems in diabetic patients. Exercise is a well-known natural method of controlling diabetes. In the real sense, majority of the people assume heavy exercise such as gymnastics and weight lifting are best exercises, small exercises such as brisk walking, cycling are the most preferable exercises in case of diabetic patients. By considering his/her health and physical status, the patient has to select specific type of exercise based on the need. Duration of exercise should depend on physical acceptability and tolerability. During night after dinner, lying exercise is one of the best methods in diabetic patient who cannot pay attention for morning walk. This exercise is useful in case of active foot diseases in uncontrolled diabetic patients. Avoid exercises in the form of walking which may worsen the condition of the foot [51].

Work-related exercises such as climbing stairs, going by walk to short distances instead of using vehicles and gardening are the best choices. Physical fitness is one of the most important criteria because diabetes shows susceptibility towards chronic complications such as silent myocardial ischemia. According to Ayurveda, diabetes is a Kapha type of disorder. About $20 \%$ of diabetics are identified and out of that 10 will be affected by Kapha, four will be affected due to Vata, and six will be resulting from pitta $[65,74,75,81,82]$.

\section{LIFESTYLE MODIFICATIONS IN DIABETES}

In certain conditions, increased blood glucose may cause diabetic retinopathy. Eye-care should be taken by consulting ophthalmologist. Daytime sleep should be avoided. Quit smoking and avoid alcohol. The risk of smoking in diabetes leads to peripheral vascular disease which may led to amputation of toes, feet or legs, high LDL cholesterol levels, and renal impairment which often leads to dialysis, worsened blood sugar control when compared to that of in non-smokers with diabetes and even causes death especially due to stroke and heart attack. Out of 100 patients newly diagnosed with diabetics, 25 patients are smokers. For the management of other comorbid disease conditions like high cholesterol level and high blood pressure, prescribed drugs should be taken regularly without fail to prevent other new complications. Nicotine replacement therapy is advised in case of patients with diabetes to quit smoking. In healthy person, the effects of smoking can be devastating, and in case of diabetics, these effects will be worsened. The blood levels will be constricted, and the cholesterol levels will be increased due to smoking [83-86]. It also often leads to impotence. Avoid consumption of junk food. Maintain body weight properly according to the body mass index. Habituate regular exercise and develop a regular pattern of sleep which can help us to reduce the chance of developing type-II diabetes [87]. Do not spend late hours by doing stressful tasks because the metabolism process responds by producing cortisol which is a stress hormone which may disturb the immune system. Sleep deprivation is also one of the causes of elevated glucose levels, which 
may be a response to stressful situation, to diminish the stresses of sleep deprivation [88].

A regular checkup by health care providers is a very important factor. Many of the experts reveal that especially the Indian colleges and school youngsters are adapted to modern lifestyle which is the major cause of type-II diabetes. Asian Indian phenotype is having higher insulin resistance when compared to others. By making the school children to adopt habits such as daily exercise, eating high protein and fiber-rich food, including fruits, nuts, and whole grains which reduce chances of occurrence of type-II diabetics. Prevention is better than cure. We could not change the gene the way how it is, but we can change our lifestyle with slight modification in our daily activities which help in prognosis of the disease condition [89].

Always wear well and protective footwear to care about the foot especially the patients with diabetes because diabetic foot is one of the factors that delay the healing of the wound in diabetic patients which has chance of acquiring infections. Drink sufficient amount of water before and after the regular exercise to prevent dehydration which may upset blood sugar levels.

It is suggestible to eat some snacks before $30 \mathrm{~min}$ of exercise and after $30 \mathrm{~min}$ of exercise. Perform the exercises which are entertaining and comfortable to an individual based on the area of interest. Regular exercises are compulsory in case of patients who adapted to sedentary lifestyle. Avoid overweight lifting and high impact activities especially in case of people with diabetic retinopathy because those activities may increase the blood pressure which may lead to bleeding in the eyes. Avoid traumatic weight-bearing exercises such as running and jogging which may lead to stress fractures or foot ulcers in case of patients with diabetic neuropathy. Stop exercise or reduce the time spending for exercise when the patient experiences symptoms such as nausea, giddiness, chest discomfort, worry, tachycardia, and breathlessness [51].

By following these approaches, besides regular usage of medications, one can lead a healthy life with very less complications. The quality of life can be increased in the patients who follow these methods when compared to those patients who do not consider any of these methods in their daily life. By selecting suitable approach based on the patient and performing them regularly, a better health condition can be achieved. The patient should not only depend on medications but it is also better to follow some of these methods which help in maintaining a healthy body. In diabetes not only diet plays a major role but also body activity, mental state, and emotional state is also important. A steady mental, physical, and emotional state helps in regulating blood glucose levels. This steady state can be obtained by following some of these methods. Apart from regulation of blood glucose levels they also help in stress management, good body texture and proper functioning of other vital organs in the body. Not only the patient, a healthy individual but it can also prefer these methods to prevent chronic illness and make their day to day life happy and healthy.

\section{AUTHOR'S CONTRIBUTIONS}

All the authors have equally contributed to the preparation of this manuscript.

\section{CONFLICTS OF INTEREST}

None.

\section{REFERENCES}

1. American Diabetic Association. Report of the expert committee on the diagnosis and classification of diabetes mellitus. Diabetes Care 1997;20:1183-97.

2. van Tilburg J, van Haeften TW, Pearson P, Wijmenga C. Defining the genetic contribution of Type 2 diabetes mellitus. J Med Genet 2001;38:569-78

3. American Diabetes Association. Standards for medical care in diabetes
2010. Diabetes Care 2010;3:S11-61.

4. Zipitis CS, Akobeng AK. Vitamin D supplementation in early childhood and risk of Type 1 diabetes: A systematic review and meta-analysis. Arch Dis Child 2008;93:512-7.

5. Defronzo RA. Banting lecture. From the triumvirate to the ominous octet: A new paradigm for the treatment of Type 2 diabetes mellitus. Diabetes 2009;58:773-95.

6. DiPiro JT, Talbert RL, Yee GC, Matzke GR, Wells BG, Posey LM, editors. Pharmacotherapy: A Pathophysiologic Approach. $8^{\text {th }}$ ed. New York: McGraw-Hill; 2011. p. 1257-8

7. Vijayan V, Jayachandran E, Sumanth MH, Brahma T, Naidu D, Rao S. Diabetes a historical perspective. J Pharm Res 2011;4:1-3.

8. DiPiro JT, Talbert RL, Yee GC, Matzke GR, Wells BG, Posey LM, editors. Pharmacotherapy: A Pathophysiologic Approach. $8^{\text {th }}$ ed. New York: McGraw-Hill; 2011. p. 1268-75.

9. Bivens L. Basic Health Care Series: Diabetes. Delhi: VIJ Books Indiapvt Ltd.; 2017.

10. Lindeberg S, Jönsson T, Granfeldt Y, Borgstrand E, Soffman J, Sjöström K, et al. A palaeolithic diet improves glucose tolerance more than a mediterranean-like diet in individuals with ischaemic heart disease. Diabetologia 2007;50:1795-807.

11. John S, Karthiga S, Parimalam SR, Chellappa AR. Nutrition and Diabetes. Coimbatore: Tamil Nadu Textbook Corporation; 2005. p. 119-31.

12. Michael Moore Classification of Foods. Available from: https:// www.webcache.googleusercontent.com/ search?q =cache: LjXX_2yekR4J: https:// patch.com/connecticut/woodbury-middlebury/ how-to-minimize-your-risk-for-type-ii-diabetes-or-manage-it $260 \mathrm{~b} 71$ $0 \mathrm{~d}+\& \mathrm{~cd}=15 \& \mathrm{hl}=\mathrm{en} \& \mathrm{ct}=\mathrm{clnk} \& \mathrm{gl}=\mathrm{in}$.

13. Abraham N, Balagopal P, Batheja R, Bhargava N, Chatterjee S, Deshpande K, et al. Indian Foods: AAPI'S Guide to Nutrition, Health and Diabetes. The Subcommittee of the Public Health Committee of AAPI. Chennai: Allied Publications Pvt. Ltd.; 2002.

14. Lung NH. Blood Institute. Your Guide to Lowering Your Cholesterol with TLC (Therapeutic Lifestyle Changes) National Institutes of Health. Bethesda, MD, USA: US Department of Health and Human Services; 2006.

15. Trumbo P, Schlicker S, Yates AA, Poos M, Food and Nutrition Board of the Institute of Medicine, The National Academies. Dietary reference intakes for energy, carbohydrate, fiber, fat, fatty acids, cholesterol, protein and amino acids. J Am Diet Assoc 2002;102:1621-30.

16. Sylvetsky A, Rother KI, Brown R. Artificial sweetener use among children: Epidemiology, recommendations, metabolic outcomes, and future directions. Pediatr Clin North Am 2011;58:1467-80, 11.

17. Garg A, Bantle JP, Henry RR, Coulston AM, Griver KA, Raatz SK, et al. Effects of varying carbohydrate content of diet in patients with non-insulin-dependent diabetes mellitus. JAMA 1994;271:1421-8.

18. Kiehm TG, Anderson JW, Ward K. Beneficial effects of a high carbohydrate, high fiber diet on hyperglycemic diabetic men. Am J Clin Nutr 1976;29:895-9.

19. Bantle JP, Wylie-Rosett J, Albright AL, Apovian CM, Clark NG, Franz MJ, et al. Nutrition recommendations and interventions for diabetes--2006: A position statement of the american diabetes association. Diabetes Care 2006;29:2140-57.

20. Nielsen JV, Joensson E. Low-carbohydrate diet in Type 2 diabetes. Stable improvement of bodyweight and glycemic control during 22 months follow-up. Nutr Metab 2006;3:22.

21. Science Daily. Original Human Stone Age Diet Is Good for People with Diabetes, Study Finds; 2007.

22. Bernstein, Richard K. Dr Bernstein's Diabetes Solution. New York: Little, Brown and Company; 1997.

23. Widanagamage RD, Ekanayake S, Welihinda J. Carbohydrate-rich foods: Glycemic indices and the effect of constituent macronutrients. Int J Food SciNutr. 2009; 60. 215-223.

24. Fenugreek Seed Importance in Diabetes. Available from: https://www. diabetes.co.uk/natural-therapies/fenugreek.html.

25. Kim HY. Nutritional intervention for a patient with diabetic nephropathy. Clin Nutr Res 2014;3:64-8

26. Dixit AA, Azar KM, Gardner CD, Palaniappan LP. Incorporation of whole, ancient grains into a modern Asian Indian diet to reduce the burden of chronic disease. Nutr Rev 2011;69:479-88.

27. Asif M. The prevention and control the Type- 2 diabetes by changing lifestyle and dietary pattern. J Educ Health Promot 2014;3:1.

28. Nuttall FQ. Dietary fiber in the management of diabetes. Diabetes 1993;42:503-8.

29. John AJ, Cherian R, Subhash HS, Cherian AM. Evaluation of the efficacy of bitter gourd (Momordica charantia) as an oral hypoglycemic 
agent a randomized controlled clinical trial. Indian J Physiol Pharmacol 2003;47:363-5.

30. Modak M, Dixit P, Londhe J, Ghaskadbi S, Devasagayam TP. Indian herbs and herbal drugs used for the treatment of diabetes. J Clin Biochem Nutr 2007;40:163-73.

31. Rai V, Iyer U, Mani UV. Effect of tulasi (Ocimum sanctum) leaf powder supplementation on blood sugar levels, serum lipids and tissue lipids in diabetic rats. Plant Foods Hum Nutr 1997;50:9-16.

32. Tiwari AK, Sahana C, Zehra A, Madhusudana K, Kumar DA, Agawane SB, et al. Mitigation of starch-induced postprandial glycemic spikes in rats by antioxidants-rich extract of Cicer arietinum Linn. Seeds and sprouts. J Pharm Bioallied Sci 2013;5:270-6.

33. Perera PK, Li Y. Mushrooms as a functional food mediator in preventing and ameliorating diabetes. Funct Foods Health Dis 2011;1:161-71.

34. De DD, Rapior S, Hyde KD, Bahkali AH. Medicinal mushrooms in prevention and control of diabetes mellitus. Fungal Divers 2012;56:1-29.

35. Landsberg L, Young JB. Sympathoadrenal system: The regulation of metabolism. In: Ingbar SH, editor. Contemporary Endocrinology. Vol. 2. New York: Plenum; 1985. p. 217-46.

36. Surwit RS, Schneider MS. Role of stress in the etiology and treatment of diabetes mellitus. Psychosom Med 1993;55:380-93.

37. Inui A, Kitaoka H, Majima M, Takamiya S, Uemoto M, Yonenaga C, et al. Effect of the kobe earthquake on stress and glycemic control in patients with diabetes mellitus. Arch Intern Med 1998;158:274-8.

38. Viner R, McGrath M, Trudinger P. Family stress and metabolic control in diabetes. Arch Dis Child 1996;74:418-21.

39. Lane JD, McCaskill CC, Ross SL, Feinglos MN, Surwit RS. Relaxation training for NIDDM. Predicting who may benefit. Diabetes Care 1993;16:1087-94.

40. Lustman PJ, Griffith LS, Clouse RE, Freedland KE, Eisen SA, Rubin EH, et al. Effects of alprazolam on glucose regulation in diabetes. Results of double-blind, placebo-controlled trial. Diabetes Care 1995;18:1133-9.

41. Lehrer PM, Woolfolk RL. Are all stress reduction techniques equivalent or do they have differential effects? A review of the comparative empirical literature. In Principles and Practices of Stress Management Techniques. New York: Academic Press; 1984. p. 404-47.

42. Lichtstein KL. Clinical Relaxation Strategies. New York: Wiley; 1988.

43. Surwit RS, van Tilburg MA, Zucker N, McCaskill CC, Parekh P, Feinglos $\mathrm{MN}$, et al. Stress management improves long-term glycemic control in Type 2 diabetes. Diabetes Care 2002;25:30-4

44. Schmidt NB, Richey JA, Zvolensky MJ, Maner JK. Exploring human freeze responses to a threat stressor. J Behav Ther Exp Psychiatry 2008;39:292-304

45. Borghouts LB, Keizer HA. Exercise and insulin sensitivity: A review. Int J Sports Med 2000;21:1-2.

46. Singh RB, Singh S, Fedacko J, Pella D, De Meester F. Pranayam Yoga Breathing Practices Modulate the Mind-Body Connection. Int J Disabil Hum Dev 2009;8:141-53.

47. Bal BS. Effects of short term practice of anuloma viloma pranayama on components of health-related fitness. Educ Prac Innov 2015;2:10-8.

48. Srivastava S, Goyal P, Tiwari SK, Patel AK. Interventional effect of bhramari pranayama on mental health among college students. Int J Ind Psychol 2017;4:29-33.

49. Nivethitha L, Mooventhan A, Manjunath NK. Effects of various Prānāyāma on cardiovascular and autonomic variables. Anc Sci Life 2016;36:72-7.

50. Singh RB, Wilczynska-Kwiatek A, Fedacko J, Pella D, De MeesterF. Pranayama: The power of breath. Int J Disabil Hum Dev 2009;8:141-53.

51. Raveendran AV, Deshpandae A, Joshi SR. Therapeutic role of yoga in Type 2 diabetes. Endocrinol Metab (Seoul) 2018;33:307-17.

52. Khedikar SG, Erande MP. Management of diabetes mellitus through aasana and pranayama. Int J Curr Med Pharm Res 2018;4:3656-60.

53. Srivastava A, Tiwari RK. Effect of yoga asanas and pranayama on diabetic adults. Int J Yoga Allied Sci 2015;4:95-101.

54. Mondal S, Kundu B, Saha S. Yoga as a therapeutic intervention for the management of Type 2 diabetes mellitus. Int J Yoga 2018;11:129-38.

55. Jindal N, Joshi NP. Comparative study of vamana and virechanakarma in controlling blood sugar levels in diabetes mellitus. Ayu 2013;34:263-9.

56. Shalinee, Mishra D, Kamal K, Gupta AK, Sharma KK. Shankha prakshalana: A yogic karma for purification. Int J Ayurvedic Herb Med 2012;2:578-81.

57. Skoro-Kondza L, Tai SS, Gadelrab R, Drincevic D, Greenhalgh T. Community based yoga classes for Type 2 diabetes: An exploratory randomised controlled trial. BMC Health Serv Res 2009;9:33.

58. Jyotsna VP, Joshi A, Ambekar S, Kumar N, Dhawan A, Sreenivas V, et al.
Comprehensive yogic breathing program improves quality of life in patients with diabetes. Indian J Endocrinol Metab 2012;16:423-8.

59. Miller CK, Kristeller JL, Headings A, Nagaraja H, Miser WF. Comparative effectiveness of a mindful eating intervention to a diabetes self-management intervention among adults with Type 2 diabetes: A pilot study. J Acad Nutr Diet 2012;112:1835-42.

60. Ricard M, Lutz A, Davidson RJ. Mind of the meditator. Sci Am 2014;311:38-45.

61. Chung SC, Brooks MM, Rai M, Balk JL, Rai S. Effect of sahaja yoga meditation on quality of life, anxiety, and blood pressure control. J Altern Complement Med 2012;18:589-96.

62. Keyworth C, Knopp J, Roughley K, Dickens C, Bold S, Coventry P, et al. A mixed-methods pilot study of the acceptability and effectiveness of a brief meditation and mindfulness intervention for people with diabetes and coronary heart disease. Behav Med 2014;40:53-64.

63. Singh S, Kyizom T, Singh KP, Tandon OP, Madhu SV. Influence of pranayamas and yoga-asanas on serum insulin, blood glucose and lipid profile in Type 2 diabetes. Indian J Clin Biochem 2008;23:365-8.

64. Thangasami SR, Chandani AL, Thangasami S. Emphasis of yoga in the management of diabetes. J Diabetes Metab 2015;6:613.

65. Youngwanichsetha S, Phumdoung S, Ingkathawornwong T. The effects of mindfulness eating and yoga exercise on blood sugar levels of pregnant women with gestational diabetes mellitus. Appl Nurs Res 2014;27:227-30

66. Sreedevi A, Gopalakrishnan UA, Karimassery Ramaiyer S, Kamalamma L. A randomized controlled trial of the effect of yoga and peer support on glycaemic outcomes in women with Type 2 diabetes mellitus: A feasibility study. BMC Complement Altern Med 2017;17:100.

67. Malhotra V, Singh S, Tandon OP, Sharma SB. The beneficial effect of yoga in diabetes. Nepal Med Coll J 2005;7:145-7.

68. Amita S, Prabhakar S, Manoj I, Harminder S, Pavan T. Effect of yoga-nidra on blood glucose level in diabetic patients. Indian J Physiol Pharmacol 2009;53:97-101.

69. Innes KE, Vincent HK. The influence of yoga-based programs on risk profiles in adults with Type 2 diabetes mellitus: A systematic review. Evid Based Complement Alternat Med 2007;4:469-86.

70. Aswathy S, Unnikrishnan AG, Kalra S. Effective management of Type 2 DM in India: Looking at low-cost adjunctive therapy. Indian J Endocrinol Metab 2013;17:149-52.

71. Mahajan AS. Role of yoga in hormonal homeostasis. Int J Clin Exp Physiol 2014;1:173-8.

72. Innes KE, Bourguignon C, Taylor AG. Risk indices associated with the insulin resistance syndrome, cardiovascular disease, and possible protection with yoga: A systematic review. J Am Board Fam Pract 2005;18:491-519.

73. Kosuri M, Sridhar GR. Yoga practice in diabetes improves physical and psychological outcomes. Metab Syndr Relat Disord 2009;7:515-7.

74. Ross A, Thomas S. The health benefits of yoga and exercise: A review of comparison studies. J Altern Complement Med 2010;16:3-12.

75. Gordon L, Morrison EY, McGrowder D, Penas YF, Zamoraz EM, Garwood D, et al. Effect of yoga and traditional physical exercise on hormones and percentage insulin binding receptor in patients with Type 2 diabetes. Am J Biochem Biotechnol 2008;4:35-42.

76. Sahay BK. Yoga and diabetes. J Assoc Physicians India 1986;34:645-8.

77. Sahay BK. Role of yoga in diabetes. J Assoc Physicians India 2007;55:121-6.

78. McDermott KA, Rao MR, Nagarathna R, Murphy EJ, Burke A, Nagendra RH, et al. A yoga intervention for Type 2 diabetes risk reduction: A pilot randomized controlled trial. BMC Complement Altern Med 2014;14:212.

79. Cui J, Yan JH, Yan LM, Pan L, Le JJ, Guo YZ, et al. Effects of yoga in adults with Type 2 diabetes mellitus: A meta-analysis. J Diabetes Investig 2017;8:201-9.

80. Hagins M, States R, Selfe T, Innes K. Effectiveness of yoga for hypertension: Systematic review and meta-analysis. Evid Based Complement Alternat Med 2013;2013:649836.

81. Sahay BK, Murthy KJR, Raju PS, Madhavi S. Effect of yogic practices on exercises tolerance in diabetes. Diabetes 1991;40:398.

82. Madhavi S, Raju PS, Reddy MV, Annapurna N, Sahay BK, Kumari DG, et al. Effect of yogic exercises on lean body mass. J Assoc Physicians India 1985;33:465-6.

83. Chong S, Ding D, Byun R, Comino E, Bauman A, Jalaludin B, et al. Lifestyle changes after a diagnosis of Type 2 diabetes. Diabetes Spectr 2017;30:43-50.

84. Khan MU. Lifestyle modification in the prevention of Type II diabetes mellitus. Oman Med J 2012;27:170-1. 
85. Sanghani NB, Parchwani DN, Palandurkar KM, Shah AM, Dhanani JV. Impact of lifestyle modification on glycemic control in patients with Type 2 diabetes mellitus. Indian J Endocrinol Metab 2013;17:1030-9.

86. Liu AY, Silvestre MP, Poppitt SD. Prevention of Type 2 diabetes through lifestyle modification: Is there a role for higher-protein diets? Adv Nutr 2015;6:665-73.

87. Sami W, Ansari T, Butt NS, Hamid MRA. Effect of diet on Type 2 diabetes mellitus: A review. Int J Health Sci (Qassim) 2017;11:65-71.

88. Knutson KL. Impact of sleep and sleep loss on glucose homeostasis and appetite regulation. Sleep Med Clin 2007;2:187-97.

89. Bhatia V, IAP National Task Force for Childhood Prevention of Adult Diseases. IAP national task force for childhood prevention of adult diseases: Insulin resistance and Type 2 diabetes mellitus in childhood. Indian Pediatr 2004;41:443-57. 